\title{
Study of Logistics Management in Workshops Based on RFID
}

\author{
XIAO Jijun ${ }^{1, a^{*}}$, SHEN Ye ${ }^{2, b}$, CHU Binbin ${ }^{3, c}$ and SHI Yaling ${ }^{4, d}$ \\ 1,2,3,4 School of Management, Guilin University of Electronic Technology, Guilin, China

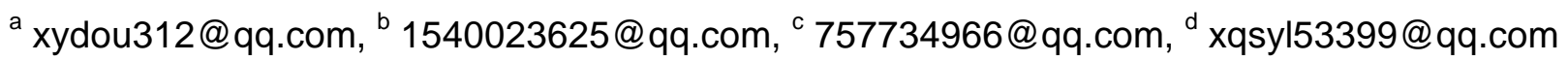

Keywords: RFID; Workshop; Production Logistics; Just In Time Production

Abstract. Manufacturing Enterprises must confront uncertainty and complexity of production areas consisting of different production elements. The traditional enterprises always rely on manually collected data and barcode data which causes inevitable error and inefficient production planning. While production logistics systems play a significant role in the supply chain. Making arrangements and deployment for the production area based on RFID which can realize real-time tracking of tagged objects and collection of instantly product information. Disruption of production can be determined and controlled, thus the real-time production plan can be set more accurate and practical. The formation of workshop network about production facilities, then production logistics information will be dynamically and punctually reflected the work in progress items. The effective integration of human, machine, material, method, environment can be promoted via RFID based production logistics.

\section{Introduction}

With the frequent changes in technology and social environment, the single manufacturing mode of flow shop can't satisfy personalized and diversified demands at rapid respond speed. Nowadays, the pull approach possessing the features of customization, low inventory and order-orientation has become the dominant pattern in transportation and production. Furthermore, product life cycles are getting shorter, customers' demands are having high uncertainty. In this case, rapid response, differentiation and cost leadership have become major competitive strategies. There are many enterprises adopting the measure focusing management on production delay or logistics postponement. The intention of these measures is to improve the uncertainty in demands, production and transportation of identical parts can be underway according to prediction, however, the discrepancy parts can be responded according to customers' needs. It is imperative that enterprises can achieve and analyze information timely. The ability to trace production logistics and response customer quickly appears particularly important. And therefore, enterprises can use RFID technology to support the modern manufacturing pattern.

\section{Fundamental principles of RFID}

Basic overview of RFID. RFID (Radio Frequency Identification) is a automatic identification technology without contact, which uses radio frequency waves to identify,track and locate objects.Multiple objects can be recognized by RFID simultaneously.Although barcode is still recognized as the main measure to identify products in the supply chain, but it is limited in readability and capability of information.In the long term,barcode is easy to be broken and possesses the drawback that information can't be changed. However,radio frequency identification technology is erasable, which can be used all day and may read several group information.Furthermore, RFID owns the advantages of automatic identification and non-human operation.

The emergence and development of RFID technology not only represents technology improvements compared with bar code,but also means the automated data entry. It can achieve information much faster than bar code technology.On the particular occasion, the status report can be created, which means less labor and more information about goods.If RFID technology were applied to the 
manufacturing,transportation and warehousing sections, the integrated and sustainable information, the standardization of data and work efficiency can be achieved.

The composition and operation principle of RFID. RFID reader and electronic tags transmit data in a non-contact and bidirectional way, which uses electromagnetic energy to realize the automatic identification and data collection, which can achieve the purpose of identifying targets and exchanging data. During the operation of RFID, reader releases radio frequency signal via antenna. Once the labeled objects enter in antenna work area, the electronic tag releases data in digital memory chips. After handling the received signals and sending them to the data management system, reader may make the processing control correspondingly.

As is shown below, Fig.1. reflects the operation principle of RFID. By using RFID technology, the efficiency of automatic data acquisition can be improved in the process of production. The transparency of information can be enhanced additionally. The real-time tracking and feedback of the target object can be realized via attaching RFID tags to them.

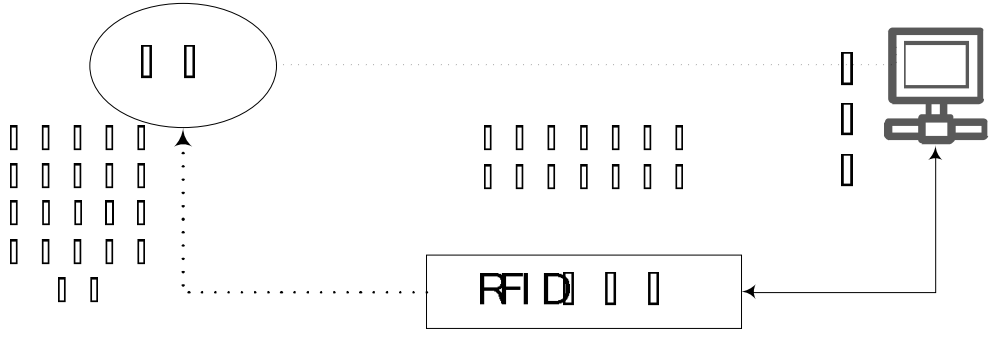

Fig.1.The sketch of RFID operation

The general situation of RFID application.Logistics flow,capital flow and information flow exist in the entire enterprise production activities.Logistics flow starts from the initial activity and reaches the final point of consumption.Capital flow ranges from downstream to upstream,and information flow appear bidirectional transmission. In order to adapt themselves to the increasingly fierce market,meet the diversified needs of customers and response to production, inventory, shelves, etc. enterprises require advanced information technology and inventory management to strengthen information sharing and tackle market demand. Fig.2. reflects the framework of the enterprise production activities . Enterprises must rely on a critical link of production logistics to improve production input and output.

In the modern supply chain management, information flow occupies the important position in the production activity. Using RFID technology can realize tracking and feedback information in raw material purchasing, processing, assembling and selling goods to customers. It will provide great impetus to improve the standard of production and service.

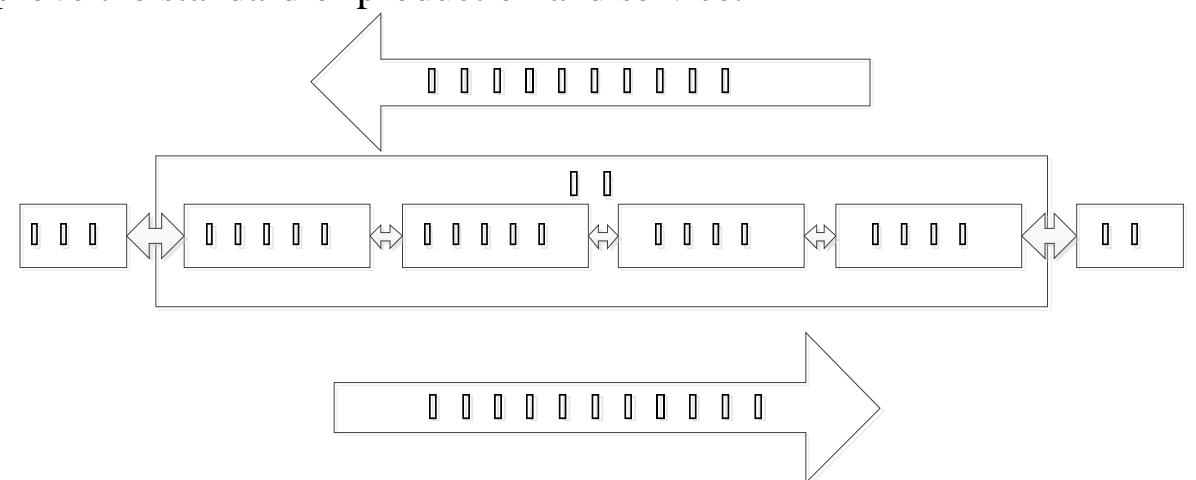

Fig.2. Enterprise Production Management Framework

In recent years, RFID technology in various fields have been used, such as services, retail, manufacturing, libraries, automobile industry. It focused on inventory management, logistics, and other aspects of the production processmanagement.

Production. RFID in the aspect of production is mainly used in automatic production line operation, using labels can quickly and effectively from the stock center to find appropriate materials and parts needed for the station, combined transport systems and transmission equipment, to achieve the transfer 
of materials, in order to achievethe raw materials, components, semi-finished products, final products in the production of complete identification in the process of tracking, greatly reducing the cost and error rate of artificial recognition,improve the efficiency of the enterprise production.In the production process to achieve timely replenishment according to the progress of production of products, but also to enhance product quality tracking and control.

Storage.In terms of inventory management, inventory information is not accurate, excess inventory resulting in increased value greater loss and inventory costs, less inventory due to out of stock, list of lost articles, to a large extent will reduce corporate profits. The introduction of RFID in storage, mainly applied in access to goods and stock inventory, the label stick in the goods after the goods input relative information of packaging or pallets; setting the reader in the warehouse, the goods out of the warehouse when the label Related information into the cargo access,you can effectively implement access control and inventory of goods.It can automatically record the storage location of the vehicle to run under warehousing and out of the library, thereby efficiently and accurately achieve rapid inventory.Meanwhile, the information on the registration of goods automated, reducing the process of manual inspection and scanning the bar code at the time of inventory, thereby enhancing the accuracy and rapidity of the job.

Transport. In the process of transport of goods and vehicles, the RFID label in road of RFID equipment installed to realize effective tracking of goods and transportation process. When the receipt of thecargo without opening the package,after reading the label information,comparing with data provided by the supplier inspection.Can be rejected inspection efficiently.

Delivery.RFID used in the distribution sectors, thus speeding up the speed of delivery and improve selection and distribution efficiency and accuracy,effectively reducing the cost.Into the central distribution center will affix RFID tags, readers will be able to read the label carton and feedback through the system, to achieve the input information and shipping records check, which checks to verify and update information.

Sales. Using RFID can also improve the retailer's inventory management,realize the timely replenishment, the transportation and inventory tracking effectively, reduce the error rate. Not only that, but also for the sale of time-sensitive monitor the validity period, the payment station for automatic scanning and billing. Each position changes in the cargo transfer process can be effective recording, real-time understanding of the actual position of the cargo, the entire track all aspects of the process.

Recycling. The use of RFID can easily find defective products, the source of substandard goods, helping recycle the products in question, through product tracking system query error process, so as to effectively transform.

\section{Customized RFID is based on real-time production logistics system}

Workshop production logistics model. Production logistics is the key link in manufacturing products in enterprise, through devoting to the people, machine, material, logistics, and to relate the suppliers to customers in the both ends of departments of materials, by-product, production into the target objects during the process of production logistics, and to relate the suppliers to customers in the both ends of departments of purchasing, warehouse, workshop, quality inspection and logistics distribution. Enterprise transforms production inputs into outputs through the production logistics, so the production logistics has a vital role in process of production and operation.

As shown in Fig.3. is a model of production logistics, from picking, manufacturing to storage, this a series of process needs real-time response, and accurate feedback information of production logistics. Using RFID technology can add accurate real time production plan to the Horizontal Logistics process of picking, processing and assembling. The effective feedback information of qualified products and unqualified products after the product testing make the defect materials and defect product be traced back. So as to improve important market competitiveness such as production flexibility, product quality, quality of service etc. 


\section{RFID Production logistics information system}

Complex production area is affected by many factors, and may be the biggest difficulty facing the customized real-time production.Before the RFID technology,many manufacturers use manual or bar code collection data,using RFID equipment makes the production area have been systematically deployed, which can be a good track feedback on products and in-time production data.In order to the labor-intensive enterprises,to control production costs would run link the warehouse,upstream suppliers and downstream distributors, making warehouse management system can provide timely and accurate information of the warehouse operation.

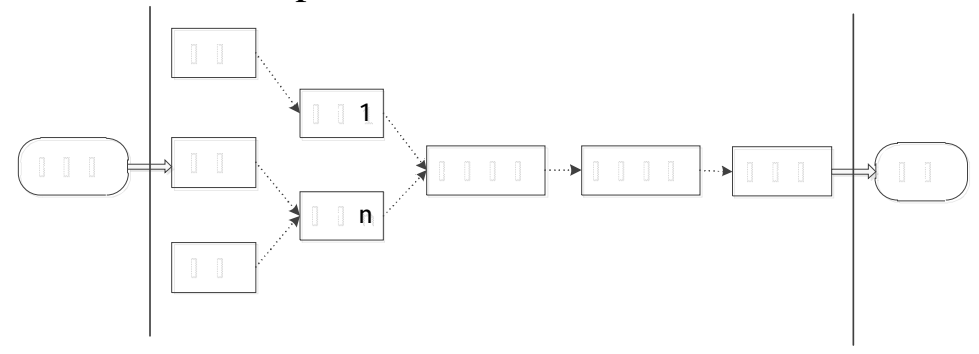

Fig.3. Production Logistics Model

In a typical information system framework,there are three main levels: manufacturing area, manufacturing execution and enterprise information system.As shown in Fig.4. is a framework for RFID information system.Enterprise information system layer contains the Enterprise Resource Planning,Product Data Management,Computer Aided Process Planning modules etc, which mainly serves for decisions of enterprise management level.

In the middle-level manufacturing execution systems can be subdivided into several functional modules,thus forming a network with key service functions.RFID middleware is primarily used to manage RFID devices, and control the data transfer between readers,tags and hardware devices. We decided to plan service execution in-time production and control production planning run,it is responsible for managing the process,so programs can most effectively implement and meet different production goals. Workshop production management real-time visual tracking service dispensing material,consumption material and the resource state of production sites had been immediately reflected,and it also has the effect of reflecting function, such as the use of analytical machines, workshop production management inventory levels.Database service provides real-time production data,and interface service acts as a bridge of share information between workshop production management real-time visual tracking service and information systems with others.Lastly the production area,which contains the automatic information recognition devices,such as RFID readers,tags,mobile devices and communication networks etc,they are mainly used to access information of real-time production.

\section{Based on the work area development of RFID}

To develop the RFID work area, the first should we consider the following issues:

(1) The actual environment of the production area and the warehouse

(2) Choosing the appropriate RFID facilities

(3)Collection and storage of data

(4) According to the new delivery order to choose the suitable materials and handling equipment

(5) Identifying and locating resources

(6) In accordance with the delivery order and material handling methods to plan out the delivery routes

(7) Based on the planned path for the combination of suitable materials to hand facilities

After basic planning was carried out on the workspace, the working area of deployment can be roughly divided into four steps. First of all, the equipment and buffers layout in the working area, which are usually equipped with a high frequency RFID Reader, their working conditions also require real-time monitoring. Cache can realize material tracking, in order to achieve a variety of materials moving track and workshop production management of inventory to be under control. Workshop logistics operators and site supervisors to provide mobile terminal devices for mobile information, this 
important information can be wireless, according to the target at different locations to get real-time updates.

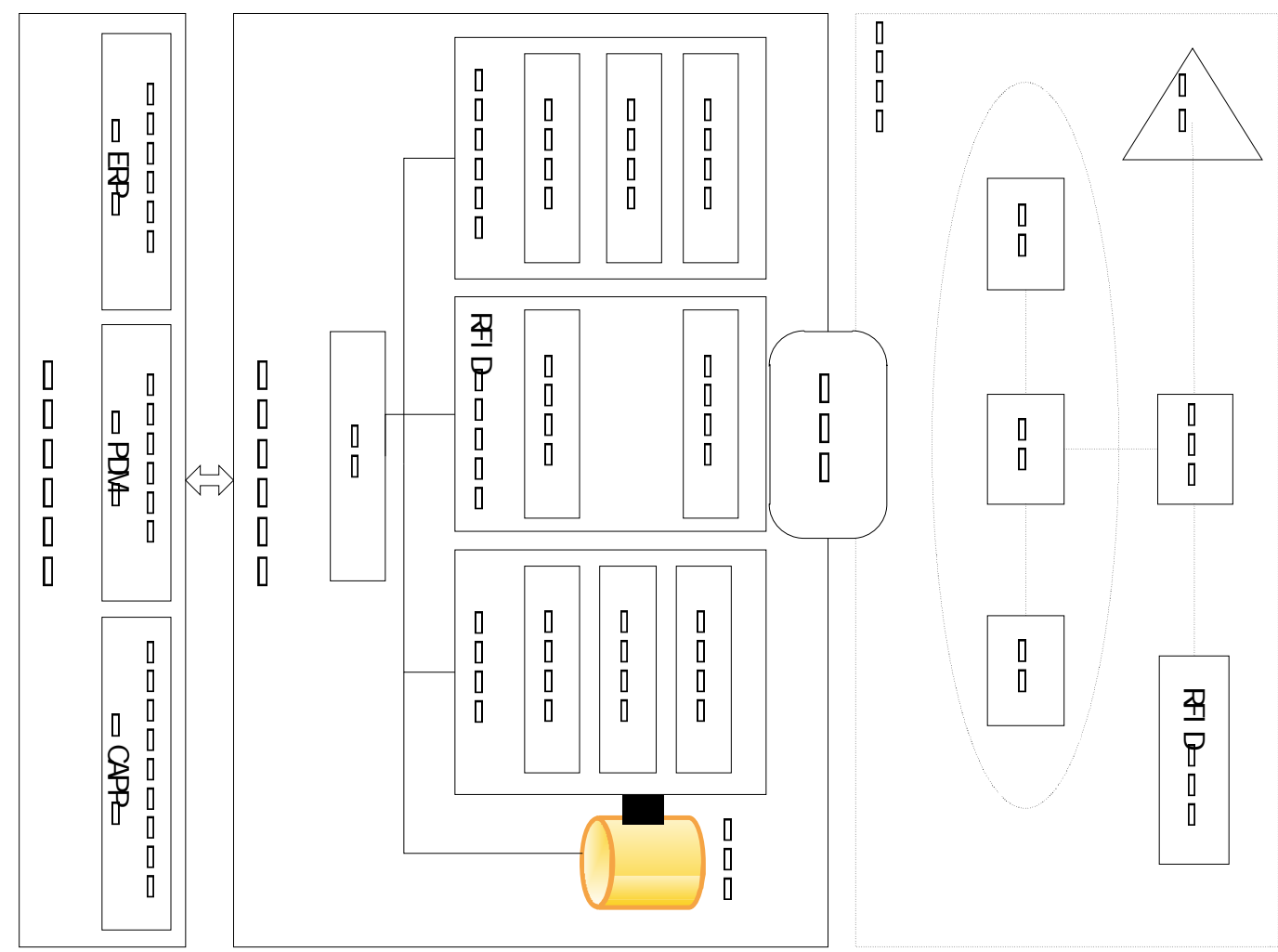

Fig.4.The RFID production logistics information system framework

Secondly, different labels are designed for the function of the detailed reason. For the important part, such as highly customized products and key components of the final finished goods, because of their importance, it is necessary to use a unique identification property of the tag correspond to the target one by one.For non-critical materials, can use the pallet label, label attached to tray, to achieve a variety of material flow monitoring. For machine operators, workshop internal and external logistics operators, the field supervisors can attached the labels to employee cards.

The third step is to deploy communication networks, FID must be combined with the wireless communication networks, in a variety of customized production area for machine layout line installation, according to the cost-benefit analysis to choose different wireless communication network standards, wireless network layout should be simple and hardware facilities to have relatively low capacity consumption.

The fourth step is process reengineering, systematically in a variety of customized production areas for the layout of the RFID equipment, the establishment of a more common real-time RFID based on a variety of customized production environment. Think the workshop as a hybrid flow shop, making instant decisions in RFID workspace provides convenience. When the label targets to carry out its logistics or start to run, according to the priority of work, set up time and processing time, and the end of the working time will be updated.

\section{Conclusion}

This article mainly introduced the RFID real-time production of customized real-time manufacturing operation system, which is different from the traditional manufacturing area of manual paper, bar code data collection, the preparation plans, will effectively avoid errors of very large amounts of data information and high inventory backlog. The use of RFID equipment will systematically to layout the production site to create a real-time manufacturing environment for Riding this kind of intelligent environments, the typical manufacturing resources are transformed into the target objects in the system, and its importance for the hierarchy, so that they can track the target and 
collect the relevant real-time data. FID instant manufacturing operation system used the real-time information to support real-time production plan making, operation and control. In the hybrid flow shop, the instant working pool and the corresponding multiple rules can be used to deal with the problem of the multi-stage.

This article is mainly engaged in the supply chain customization production of several aspects of the application of RFID innovation. FID technology will systematically layout of the manufacture of different targets, through this layout and different label designs will avoid wrong tendency of traditional data collection, fatigue and a lot of time consumption, saving the cost and conforming with the principle of economy applicable. Will affect the normal plan of disturbing factors can also by RFID for harvest and feedback to the system in order to guarantee to take the corresponding decision immediately. The application of this model can make the enterprise and the whole supply chain in terms of quality and production logistics to obtain better benefits. After the initial data collected by RFID technology will combine with the logistics in to form valuable information, so any material movement can be captured and presented to decision makers, thus establish differentiation strategy to make the inventory down to a minimum, and the production efficiency is improved.

\section{References}

[1] Worapot Jakkhupan, Somjit Arch-int, Yuefeng Li. Business process analysis and simulation for the RFID and EPC globe network enabled supply chain :A proof-of-concept approach [J].Journal of Network and Computer Applications, 2011, 34 : 949-957.

[2] James C.Chen, Chen Huan Cheng, PoTsang B.Huang. Supply Chain management with lean production and RFID application: A case study [J]. Expert Systems with Applications,2013,40: 3389-3397.

[3] Ray Y.Zhong, Q.Y.Dai, T.Qu, G.J.Hu, George.Q.Huang. RFID enabled real-time manufacturing execution system for mass-customization production [J].Robotics and Computer-Integrated Manufacturing,2013,29: 283-292.

[4] Vladimir Todorovic,Marius Neag,Milovan Lazarevic. On the usage of RFID Tags for Tracking and Monitoring of Shipped Perishable Goods [R].Science Direct, 2014,69: 1345-1349.

[5] Xie Yurong,Liu Ying,Cheng Xiangxun. Based on RFID door manufacturing enterprise integrated workshop production management system [J]. Design and research,2013,7(40),26-32.

[6] Wang Chunfeng, Shao Ming, Zhang Yiquan, Shang Qing.Based on the research of the Production logistics of auto manufacturing enterprise of RFID [J].Logistics technology ,2007(1),103-105.

[7] NiLin. based on RFID information integration model of Auto production line and key technology research[D].Doctoral Dissertation of Chongqing University,2010

[8] Song Ancheng, qiao, hellmann. Emu maintenance spare parts supply chain management based on RFID technology[J]. Railway transportation and economy,2006,28(11),57-59.

[9] Long Yanli.The application of RFID in aviation logistics[J].Market modernization 2007,(50),141-142.

[10] Pan Hui, Ying Min, Xu Qiao, Zhao Xin, Wang Haiyan. The application of RFID in the en-terprising production logistics[J].The world of science and technology,2012,31,23-25. 